\title{
Non-Syndromic Multiple Supernumerary Teeth in a Child: A Rare Case Report
}

\author{
Ribeiro MC ${ }^{1 *}$, Kato $\mathrm{RB}^{2}$, Amaral $\mathrm{MBF}^{1}$, Azenha \\ $\mathbf{M R}^{3}$ and Mesquita RA ${ }^{1}$ \\ ${ }^{1}$ Department of Oral Surgery and Pathology, School of \\ Dentistry, Universidade Federal de Minas Gerais, Belo \\ Horizonte, Brazil \\ ${ }^{2}$ Department of Oral and Maxillofacial Surgery and \\ Periodontology, School of Dentistry, Universidade de São \\ Paulo, Ribeirão Preto, Brazil \\ ${ }^{3}$ Oral and Maxillofacial Surgeon at Stomatology \\ Department, University of Sao Paulo (FORP/USP), Brazil \\ *Corresponding author: Michel Campos Ribeiro, \\ Universidade Federal de Minas Gerais, Faculdade de \\ Odontologia, Av. Antônio Carlos, 6627, Belo Horizonte, \\ MG, Brazil
}

Received: March 30, 2017; Accepted: April 21, 2017; Published: April 28, 2017

\section{Introduction}

Multiple supernumerary teeth (MST) has been reported in the literature over the years as well-recognized phenomenon and it has defined by tooth number excess compared with deciduous or permanent dentition $[1,2]$. Generally, supernumerary teeth present morphology and volumetric anomalies which can be erupted or nonerupted $[3,4]$.

MST can be present in the permanent dentition or deciduous dentition being twice as often in the permanent dentition, more prevalent in man (2:1) and the maxilla is the most frequent location $(1,3: 1)$ [5]. MST is a common condition, when the patient has Cleidocranial Dysplasia or Gardner Syndrome. However, MST is rare in non syndromic patients $[1,3,4]$.

The present study aims to describe a rare case of MST in a nonsyndromic Brazilian child with fourteen elements presented in all quadrants which are removed surgically.

\section{Case Presentation}

A 13-year-old Brazilian girl with non-contributory medical, cultural and social records was referred to the Oral and Maxillofacial Surgery clinic, school of Dentistry, Universidade de São Paulo, by a private orthodontist. Through extraoral examination did not show any abnormality. Through clinical examination was observed malocclusion, diastema among incisives and absence of teeth 13 and 34 (Figure 1). Panoramic radiographic showed impacted teeth: 14 supernumerary teeth, 4 wisdon teeth and 2 teeth of permanent dentition (13 and 34) (Figure 2). The patient's medical history was investigated by a geneticist, however, association with syndromes were not confirmed. It was realized investigation about presence of MST in the patient parents by clinical and radiographic examination and no alterations were presented in the patient's family. The patient had all impacted teeth removed, including fourteen supernumerary teeth and four wisdon teeth, under general anesthesia. The first quadrant presented four supernumerary teeth (1 fourth molar, 2 conical and 1 tuberculate) and 1 wisdon (18). The second quadrant showed 1 supernumerary teeth (fourth molar) and 1 wisdon (28). The third quadrant showed 5 supernumerary teeth (1 fourth molar and four supplemental) and 1 wisdon (38). The fourth quadrant showed four supernumerary teeth ( 1 fourth molar and 3 supplemental) and 1 wisdon (48) (Figure 3). The patient had no complications in the follow-up period.

\section{Discussion}

The aim of this paper was to present a case of Brazilian child girl with a record number of MST described in the scientific literature in our knowledge. All quadrants were stricken and fourteen supernumerary teeth and four wisdon teeth were removed surgically by general anesthesia. The presence of MST are rare in non-syndromic patients, especially when affect all mouth quadrants. The present study situation is extreme if compared with Gomes et al [5]. Which reported only nine supernumerary teeth in your study.

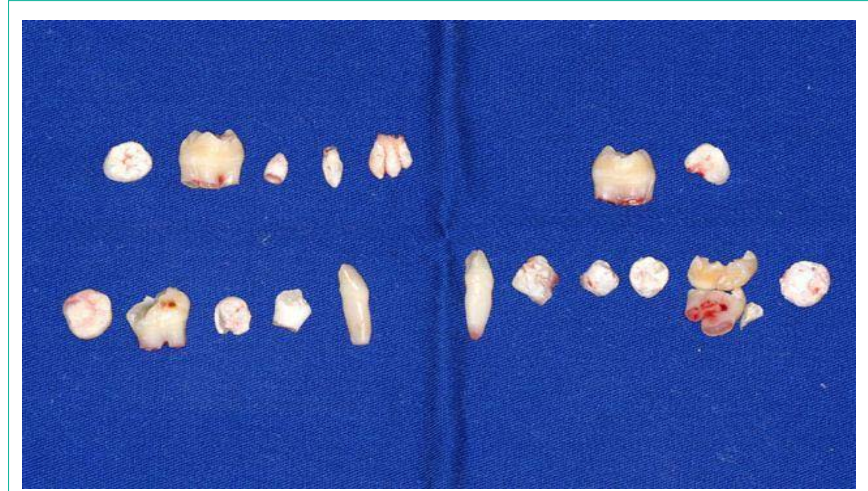

Figure 1: Clinical examination.
J Dent App - Volume 4 Issue 1 - 2017

ISSN : 2381-9049 | www.austinpublishing group.com

Ribeiro et al. ( ) All rights are reserved
Citation: Ribeiro MC, Kato RB, Amaral MBF, Azenha MR and Mesquita RA. Non-Syndromic Multiple Supernumerary Teeth in a Child: A Rare Case Report. J Dent App. 2017; 4(1): 370-371. 


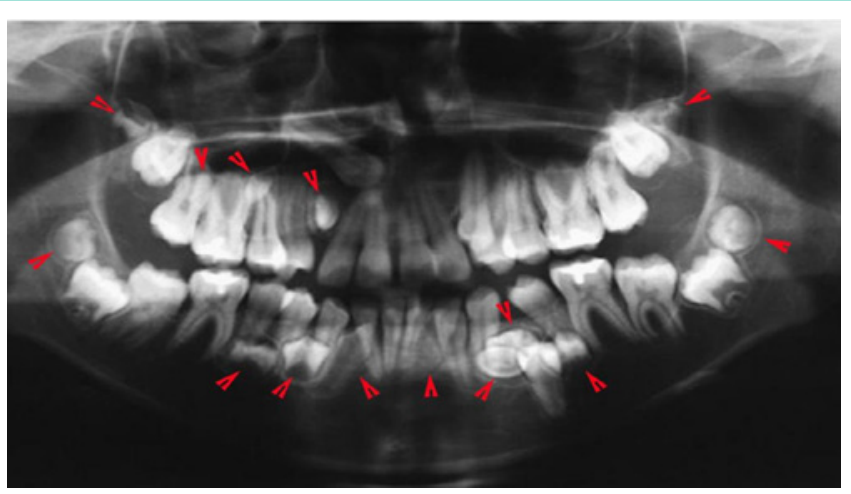

Figure 2: Panoramic radiograph showing fourteen MST (red arrows head) and four wisdon teeth.

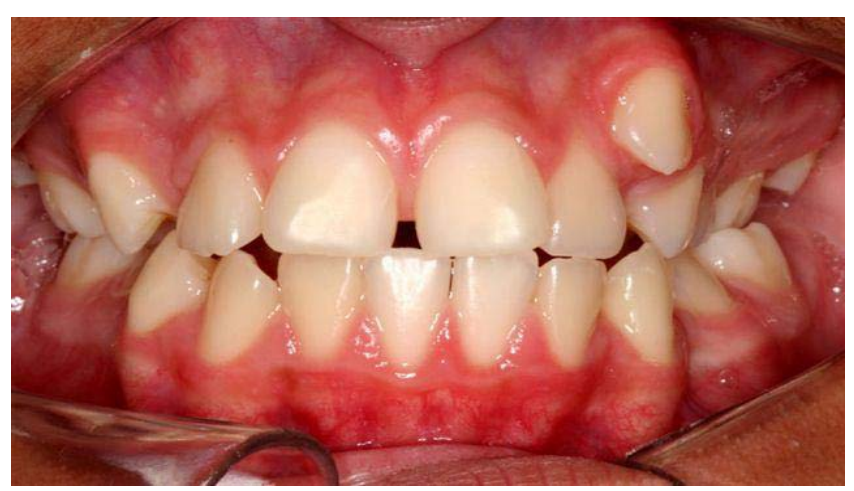

Figure 3: MST after surgery.

In the prior literature, MST were presented mainly in the maxilla with slight predilection for man gender, however in this case, the major number of supernumerary teeth were presented in the mandible of a girl (9) and only five in the maxilla [1-3,5].

The classification of MST according to the morphology is: 1) conical, 2) tuberculate, and 3) supplemental. Therefore, other classification is according to the intraoral position of the tooth: 1) Mesiodens, 2) Paramolar, 3) Distomolar, and 4) Parapremolar $[4,5]$. The prevalence rate of MST varies on population from 0,1 to $3,6 \%$ [1]. The main morphology of MST reported in the prior literature is conical shape, followed by tuberculate and supplemental [5]. In the present case report, the supplemental type was the most frequently encountered followed by conical type and only one was the tuberculate type.
MST is generally asymptomatic and discovered in eventual radiographic exams. More common complications related to these teeth are: 1) eruption chronology alteration, 2) cyst development, 3) adjacent tooth resorption, 4) permanent tooth displacement, 5) occlusal disturbance, 6) crowding tooth, and 7) diastema [3,5].

Surgical management is commonly and acceptable in literature, despite this kind of treatment may cause damage in adjacent structures [1]. The patient needed orthodontic treatment, therefore, in this case the surgical indication was clear. However, many cases can be treated by conservative manner with clinical and radiographic outpatient control [1].

Surgical complications had been reported in the literature, therefore, care with some points should be observed between them: 1) apical stage of adjacent teeth, 2) pictures in three planes provided by cone-beam CT scans help to determine the appropriate surgical approach. These points should be observed to decrease surgical trauma on the adjacent hard and soft tissues.

Bullet Points:

1. Rare condition of multiple supernumerary teeth in a non syndromic patient;

2. Record number of 14 supernumerary teeth in the same patient;

3. Surgically treatment about all supernumerary teeth performed under general anesthesia.

\section{References}

1. Batra $P$, Duggal R, Parkash H. Non-syndromic multiple supernumerary teeth transmitted as an autosomal dominant trait. J Oral Pathol Med. 2005; 34: 621-625.

2. Shafer WG, Hine MK, Levi BM. Tratado de patologia bucal. In: Distúrbios do desenvolvimento das estruturas bucais e parabucais. $4^{\mathrm{a}}$ ed. Rio de Janeiro: Guanabara Koogan, 1987: 41-46.

3. Rajab LD, Hamdam MA. Supernumerary teeth: review of the literature and survey of 152 cases. Int J Paediatr Dent. 2002; 12: 244-254.

4. Inchingolo F, Tatullo M, Abenovali FM, Marelli M, Inchingolo AD, Gentile M, et al. Non-syndromic multiple supernumerary teeth in a family unit with a normal karyotype: case report. Int J Med Sci. 2010; 7: 378-384.

5. Gomes CO, Drummond SN, Jhan BC, Abdo EN, Mesquita RA. A survey of 460 supernumerary teeth in Brazilian children and adolescents. Int J Paediat Dent. 2008; 18: 98-106.

\footnotetext{
J Dent App - Volume 4 Issue 1 - 2017

ISSN : 2381-9049 | www.austinpublishing group.com

Ribeiro et al. (C) All rights are reserved
}

Citation: Ribeiro MC, Kato RB, Amaral MBF, Azenha MR and Mesquita RA. Non-Syndromic Multiple Supernumerary Teeth in a Child: A Rare Case Report. J Dent App. 2017; 4(1): 370-371. 